\title{
A clínica de Ludwig Binswanger inspirada no Dasein de Heidegger e na fenomenologia genética de Husserl
}

Ludwig Binswanger's clinic inspired by Heidegger's Dasein and Husserl's genetic phenomenology

Juliana Pita*1

Virginia Moreira*2

A clínica fenomenológica de Ludwig Binswanger propõe uma nova compreensão sobre a psicopatologia ao realçar a importância na história de vida do paciente. Encontra-se dividida em três fases mostrando a fertilidade de seus estudos psicopatológicos após a leitura de Ser e tempo e através da influência husserliana, com o intuito de esclarecer a constituição da experiência delirante. Este artigo tem como objetivo apresentar dois casos clínicos, Lola Voss e Suzanne Urban, para ilustrar a contribuição oferecida por Ludwig Binswanger à psicopatologia fenomenológica em sua segunda e última fase.

Palavras-chave: Binswanger, psicopatologia fenomenológica, casos clínicos, delírio

*1,2 Universidade de Fortaleza - Unifor (Fortaleza, CE, Brasil). 


\section{Introdução}

A clínica fenomenológica de Ludwig Binswanger propõe uma nova abordagem psiquiátrica da psicose ao realçar a importância da história de vida de pacientes no que se refere à patologia. Sua experiência psiquiátrica amadurece em Bellevue, através de sua especialidade no atendimento com esquizofrênicos (Fédida, 1970; Kuhn, 2002; Tatossian, 1979/2006; Gros, 2009; Cabestan, 2011; Cabestan \& Dastur, 2011; Chamond, 2011; Huygens, 2011; Pita \& Moreira, 2013).

Sob o olhar crítico de Binswanger (1922/1971) a psiquiatria clássica limita seu foco na busca por causas e pela natureza de uma patologia. Diante disto, nos apresenta a psicopatologia fenomenológica, na qual os sintomas devem ser compreendidos não apenas com uma proposta teórica, mas em sua totalidade, como uma forma de existência e do estar-no-mundo do psicótico. A psicopatologia fenomenológica de Binswanger oferece ferramentas para acessar este mundo vivido, encontrando-se para aquém do sintoma e de suas causas. Além de sua formação médica, Binswanger recorre à filosofia (Chamond, 2011; Holanda, 2011) e se ancora, principalmente, nas fenomenologias de Edmund Husserl e Martin Heidegger, com o desejo de desenvolver a contribuição da fenomenologia à psiquiatra tradicional. Nesse contexto, desenvolve a antropologia fenomenológica, inicialmente sob influência dos textos da fenomenologia transcendental de Husserl, como fundamento da psicopatologia fenomenológica.

Chegar mais perto da obra psicopatológica de Binswanger é se deparar com um pensamento fenomenológico em mudança, quer dizer que, ao sofrer influências de Husserl e Heidegger, podemos identificar momentos distintos ao longo de sua clínica. Tatossian (1979/2006) e Pita e Moreira (2013) apresentam o pensamento fenomenológico binswangeriano dividido em três fases: I) Primeiro Binswanger, com forte presença da fenomenologia transcendental de Husserl; II) Binswanger após a leitura de Ser e tempo, ancorado na filosofia existencial de Heidegger e III) Último Binswanger, em seu retorno à fenomenologia genética do último Husserl. 


\section{ARTIGOS}

Anterior a essas três fases, Gros (2009) aponta a fase psicanalítica, marca do início da clínica de Binswanger. Holanda (2011) destaca, ainda, uma quarta fase, a pré-fenomenológica, pois ao se afastar da psicanálise freudiana, Binswanger se aproxima teoricamente de Kant e Natorp. Não se restringindo apenas à influência teórica, Gros (2009) também separou o percurso teórico de Binswanger em dois períodos característicos: I) período de formação e construção de seu pensamento (1907-1957), momento das presenças teóricas de Freud, Husserl e Heidegger; e II) período criativo (1960-1965), no qual Binswanger explorou estudos psicopatológicos influenciados pela fenomenologia genética husserliana, especialmente no final de suas obras, Mélancolie et manie e Délire.

Neste artigo tomamos como base as três fases demarcadas por Tatossian (1979/2006) e Pita e Moreira (2013). Na primeira fase, a fenomenologia husserliana, para o primeiro Binswanger, representa apenas uma ferramenta metodológica e não se utilizava como ponto de vista psicopatológico (Gros, 2009; Tatossian, 1979/2006; Pita \& Moreira, 2013). Após 1930, a leitura de Ser e tempo, o destaque da filosofia de Heidegger no pensamento fenomenológico de Binswanger pode ser encontrado na maioria de seus textos. Esse é o período de maior produção escrita de Binswanger, de tal forma que alguns autores reconhecem apenas a influência de Heidegger nas obras de Binswanger e descartam a importante presença de Husserl, principalmente, na última fase. Nesse terceiro período, já no final de sua vida, Binswanger retoma os escritos husserlianos com um viés interpretado pelo fenomenólogo húngaro Wilhelm Szilasi, no livro Introduction à la Phénoménologie d'Edmond Husserl, de 1959. Nessa fase encontramos seus dois últimos livros, Mélancolie et manie e Délire (Tatossian, 1979/2006; Pita \& Moreira, 2013).

Este artigo busca ilustrar o pensamento fenomenológico clínico de Binswanger na segunda e terceira fases com a discussão de dois casos clínicos de pacientes esquizofrênicas delirantes — Lola Voss e Suzanne Urban. O caso Lola Voss consiste no quarto dos cinco estudos sobre esquizofrenia publicados no livro de Binswanger de 1957, Schizophrenie, representando a fertilidade dos estudos psicopatológicos de Binswanger após a leitura de Ser e tempo. Trata-se de um quadro obsessivo esquizofrênico em associação a um delírio de perseguição, analisado em uma perspectiva daseinsanalítica.

O segundo caso discutido neste artigo retrata o delírio de Suzanne Urban, ilustrando a transição entre a segunda e a terceira fases, ou seja, a importância tanto da filosofia de Heidegger como de Husserl para Binswanger. Esse caso também é discutido em Schizophrenie e retomado em seu último livro Délire, de 1965, e em uma edição francesa de 2004, Le cas Suzanne Urban: étude 
sur la schizophrénie, quando Binswanger pretende avançar nas contribuições oferecidas pela daseinsanálise e busca a constituição da experiência delirante sob a lente da fenomenologia genética de Husserl (Gros, 2009; Tatossian, 1979/2006; Pita \& Moreira, 2013).

\section{Lola Voss: uma fobia por vestidos analisada sob a lente do Dasein}

A compreensão fenomenológica da existência esquizofrênica delirante de Lola significa, para Binswanger, partir dos relatos da história de vida dessa paciente, o que consiste em uma das principais contribuições de sua clínica fenomenológica. Aos 20 anos, Lola inicia um namoro com um médico por quem estava apaixonada, mas esse relacionamento não é aceito por seu pai. Com essa rejeição, a jovem se nega a ingerir alimentos, mostrando-se triste e deprimida. Aos 24 anos, interna-se em Bellevue, embora não se considerasse doente. Apresentava boa capacidade intelectual abstrativa, era inconsequente e tinha pouco interesse em trabalhar. Seus comportamentos infantis indicavam um desenvolvimento mental inadequado para sua idade. Além disto, evitava se relacionar com outros pacientes da clínica, preferindo se isolar para pintar ou ler um livro.

Binswanger (1965) descreve modos simultâneos de estar-no-mundo do homem, apresentando três tipos de experiência no mundo: 1) Umwelt, o mundo de contato com os outros, como o que está ao nosso redor, o mundo natural; 2) Mitwelt, o mundo dos inter-relacionamentos, do Ser-com os outros; e 3) Eigenwelt, nosso mundo próprio, a percepção que temos de nós mesmos, do nosso corpo. Os homens em movimento saudável experienciam esses três mundos em sua existência, quando há alguma evitação de vivenciar um desses mundos, encontramos uma paralização existencial patológica.

Lola não se sentia completamente vazia de afetos e sentimentos, mas procurava se proteger do mundo para evitar a angústia por existir neste mundo que lhe oferecia tanto sofrimento. Com esta conclusão, Binswanger (1965) descreve a história de vida de Lola para, assim, conhecer a alteração dessa existência ao viver em constante angústia e medo de romper a fina camada de gelo que a sustentava no mundo natural, o Umwelt. Para que a existência de Lola não desmoronasse, ela precisava de um apoio, de "muletas" (p. 128) que a sustentassem nesse mundo.

Em Ser e tempo, a proposta da analítica do Dasein de Heidegger é revelar as estruturas existenciais da existência humana: espacialidade, temporalidade, queda, cuidado etc. Chamond (2011) lembra que as estruturas 


\section{ARTIGOS}

existenciais fazem parte da essência humana, assim, devem estar presentes na vida do homem. Nos psicóticos mais comprometidos, como Lola, essas estruturas existenciais também aparecem, pois o psicótico não as perde, mas elas se apresentam com alterações.

Ao utilizar o conceito heideggeriano de Dasein Binswanger pretendia ampliar seus estudos sobre as existências alteradas dos psicóticos. Conforme Teixeira (1997), Binswanger emprega a alteração do Dasein como fruto da modificação da realização do Ser. Assim, esse Dasein perturbado na psicose se torna limitado, vazio e sem brilho, determinando a existência de uma patologia, a qual se caracteriza pela perda de cor e brilho, promovendo uma limitação rígida desse Dasein no mundo, como encontramos no caso Lola.

O mundo adquire um significado especial para Lola por ser gerador de angústia. Ela acreditava decifrar as informações do destino e reconhecer seus avisos. Assim, "este destino que tão abertamente mostra ser proveniente do aterrorizante, significa ao mesmo tempo uma defesa contra a irrupção do aterrorizante em seu descarnado mistério" (Binswanger, 1965, p. 141). Esse movimento existencial de Lola é originado de conexões entre os objetos e as coisas ruins que poderiam acontecer. Para ela, os vestidos carregavam os principais elementos reveladores de seu futuro.

As experiências esquizofrênicas apresentam uma estrutura temporal chamada ante festum, pois se trata de um adiantamento do futuro. $\mathrm{O}$ esquizofrênico é esquizofrênico devido à sua consciência ante festum o separar do fundamento da experiência e se transformar em um adiantamento em direção a um futuro transcendente vazio. Esse adiantamento do futuro se manisfesta em sua "impossibilidade de habitar nas coisas": denominada por Binswanger de dissolução da coerência da experiência natural e por Blankenburg de perda da evidência natural (Bin, 1976/1998).

Para Lola, o vestido novo, ou qualquer representante de uma novidade, significava a chegada de uma desgraça. Por ter dificuldade em se relacionar com qualquer novidade, ela permanecia em uma constante interrupção do inesperado. Os vestidos determinam os direcionamentos espaciais de Lola, assim, sua espacialização acontece de uma forma "mágica" (Binswanger, 1965, p. 161), já que seu Dasein está vinculado a um si estranho a ele. O primeiro momento do delírio de Lola aparece em seu medo relacionado exclusivamente aos vestidos e às pessoas que os vestem. Em um segundo momento, esse medo se amplia para todos que a circundam, destacando-se aí a total invasão do Dasein pelo aterrorizante e ocasionando um esvaziamento existencial. Assim, a fobia por vestidos é o anúncio de um "delírio de vestidos" (Binswanger, 1965, p. 179). 
Através da análise da existência esquizofrênica delirante de Lola Voss, Binswanger (1965) sublinha a falta de esclarecimento da psicopatologia tradicional em relação ao fenômeno do delírio, tema este compreendido como um enigma para a psiquiatria clássica. Por isto, a análise do "delírio de vestidos" (Binswanger, 1965, p. 179) de Lola representa uma das principais contribuições da psicopatologia fenomenológica de Binswanger por buscar a compreensão da forma de estar-no-mundo do delirante. $O$ conceito heideggeriano de Dasein foi fundamental para Binswanger (1922/1971), pois lhe ofereceu a possibilidade de apreender o modo das formas psicóticas singulares. Com essa contribuição, a experiência psicótica desocupa o lugar de objeto para ser o sujeito da psiquiatria (Tatossian, 1979/2006; Gros, 2009; Cabestan \& Dastur, 2011; Pita \& Moreira, 2013).

\section{Suzanne Urban e o teatro do terror: uma primeira análise existencial inspirada no Dasein}

O caso clínico de Suzanne Urban foi duplamente analisado: em um primeiro momento, Binswanger elaborou uma compreensão fenomenológica a partir da influência de conceitos heideggerianos em Ser e tempo. Em seguida, utiliza-se da fenomenologia husserliana visando alcançar a constituição dessa experiência esquizofrênica.

Binswanger (1952/2004) apresenta o sofrimento de Suzanne na medida em que relata as etapas biográficas de seu sofrimento, além de sinalizar a "pulsão existencial exclusiva do terror, da destruição ou do aniquilamento, mostrando o encaminhamento biográfico e a consequência até o estágio terminal que justamente é representado pelo delírio de perseguição pluralizado" (p. 9). A análise do Dasein de Suzanne mostra o desejo de Binswanger de compreender o delírio de perseguição na esquizofrenia, pois para alcançar o delírio esquizofrênico é imprescindível a compreensão da "estrutura do Dasein como ser-no-mundo" (p. 13). Ao questionar o Dasein, um entrave surge: o Dasein não se expressa claramente, pois apresenta diversas formas de estar-no-mundo, não podendo ter como base para análise o corpo exterior e individual deste homem, mas seu corpo vivido, não se limitando, portanto, apenas às manifestações dos próprios sentimentos do paciente, mas devendo atingir suas experiências vividas.

Devemos partir da experiência do psicótico que, ao mesmo tempo, é seu corpo vivido que vive, habita e se manifesta nesse corpo, assim, procura o 
vivido corporal do paciente sem precisar sair de sua existência. Para alcançar a existência do psicótico, Binswanger entende a ultrapassagem das barreiras da fisiologia, por causa de sua objetividade, pois não é seu foco, expondo que a compreensão da esfera corporal não deveria sair do campo do fenômeno, ou seja, da própria existência. Para Coelho Junior (2001), o alcance da compreensão feita por Binswanger sobre o homem como seu corpo vivido é permitido com a superação da cisão entre interno e externo.

Conforme apresentado por Gros (2009) e Cabestan (2011), a psicoterapia daseinsanalítica de Binswanger oferece uma nova maneira de articulação com a dimensão da corporeidade, além de designar uma modalidade particular de existência na qual o doente se encontra limitado, retirando de cena o corpo objetivo (Körper) para trazer a noção de corpo vivido (Leib), onde a principal diferença entre Körper e Leib passa a ser a experiência intersubjetiva, apresentada por Binswanger através da noção de nostridade.

Suzanne era descendente de uma família judaica, casada, sem filhos e a terceira entre quatro irmãos. Após uma consulta de rotina, seu companheiro foi diagnosticado com câncer de bexiga e essa descoberta provocou alteração de humor, tristeza e muita aflição em Suzanne. Ela chorava constantemente, desconfiava de todos; para ela, as pessoas eram más e os médicos não cuidavam bem de seu marido (Binswanger, 1952/2004).

Suzanne se encontrava presa em uma "crise vital" (p. 36) agravada ao sentir um enorme medo e insegurança com a descoberta do câncer de bexiga em seu marido. Binswanger (1952/2004) aponta esse diagnóstico como o desencadeador de uma mudança existencial em Suzanne, pois ela vivia em um mundo familiar seguro e fluído que se tornara estranho e desconhecido a partir da citada doença. O "conteúdo vital” (p. 38) de Suzanne começa a ser dominado por um único tema, o câncer de seu marido, ou seja, paraliza o movimento existencial de Suzanne. Assim,

o tema oriundo da cena original já se ampliou, o que significa que ele se apossou totalmente do Si próprio da doente. Esse Si próprio, é verdade, luta ainda contra o tema, esforça-se ainda para dominá-lo e para se defender diante dele mobilizando toda sua energia, porém, cada vez mais, ele se encontra aspirado e absorvido pelo tema. (Binswanger, 1952/2004, p. 38)

Com essa imobilização de sua existência na cristalização do tema da doença do marido, um monólogo é construído e "Suzanne Urban não tolera nenhuma outra conversa a não ser a dela mesma, de fato, não se interessa por mais nada que o câncer de seu marido" (Binswanger, 1952/2004, p. 40). Essa cristalização do tema exclui o Umwelt do Dasein e Suzanne se encontra 
em uma "cegueira presunçosa de $\mathrm{Si}$ " (p. 39) manifestada em sua constante dedicação aos cuidados de seu marido.

Nessa segunda fase, a desproporção antropológica é uma das principais características da clínica fenomenológica de Binswanger. Na presunção, uma das formas destas desproporções existenciais do homem, este se encontra preso e distante do contato com o mundo comum, como acontece com os esquizofrênicos, em especial, com Suzanne. É "uma forma de cegueira do Dasein" (Binswanger, 1952/2004, p. 41) e a análise de Binswanger sugere um "mergulho no Dasein" (p. 41) que se encontra entregue aos outros, sem controle e confiança em Si, sendo identificado em Suzanne através do desejo de matar seu marido e depois se suicidar como tentativa de findar seu sofrimento e assumir o controle da existência de seu Dasein.

\section{Suzanne Urban e sua experiência delirante: uma segunda análise ampliada com a fenomenologia genética}

O mundo delirante de Suzanne Urban representa uma "luta psíquica 718 humana de fluídos" (Binswanger, 1965/2010, p. 91) sem estar relacionado a uma intuição autêntica nem a uma percepção autêntica. Com isto, "o trágico próprio na existência delirante se originava no curso mecanizado vazio da transcendência e igualmente da receptividade pura" (p. 91), sendo possível identificar uma transformação psíquica e uma mecanização do mundo. Nessa segunda análise do delírio de Suzanne Urban, reconhecemos a influência da fenomenologia genética do último Husserl na clínica fenomenológica de Binswanger, o que é característico de sua terceira fase (Pita \& Moreira, 2013; Tatossian, 1979/2006). Ele analisa aspectos intuitivos e perceptivos para detectar suas falhas em relação aos aspectos temporais.

Para Suzanne, o diagnóstico de câncer significou o primeiro passo de sua futura separação do mundo com os outros (Mitwelt), pois sabia que seu marido estava prestes a falecer. Essa possível separação do marido possibilitou o aparecimento de suas "fábulas delirantes" (p.95), as quais permitiam o conhecimento dos temas específicos dominantes de seu Dasein delirante. Binswanger (1965/2010) ainda apontava que o início dessas fábulas retirava o apoio do Dasein de Suzanne no mundo natural (Umwelt), embora seu interesse se direcionasse ao "abalo da constituição da consciência" (Binswanger, 1965/2010, p. 96) de Suzanne. 


\section{ARTIGOS}

A compreensão psicopatológica desenvolvida por Binswanger ao se inspirar na fenomenologia genética de Husserl traz ferramentas de avanços aos estudos elaborados com a Daseinsanálise. Por mais que Binswanger reconhecesse limites em sua análise existencial do Dasein, ele não desejava descartar as contribuições oferecidas pela primeira análise da existência esquizofrênica delirante de Suzanne, mas se dispunha a alcançar um outro aprofundamento com a fenomenologia genética husserliana.

A análise fenomenológica genética aponta o "esqueleto do delírio" (Binswanger, 1965/2010, p. 103) e facilita a compreensão da "estrutura cristalina das formações delirantes" (p. 103) através das distorções de percepção, memória e fantasia, as quais originam um "esquema mecânico, rígido, funcionando no vazio" (p. 104). Binswanger (1965/2010) compara essa mecanização da paciente a um animal, por estar oposto ao Dasein do homem, já que este funcionamento mecânico desconstrói o fluxo da experiência humana e altera percepção, memória e fantasia provocando distorções temporais.

Em Suzanne não se encontra um fluxo temporal autêntico nem intencionalidade aberta que identificamos em pessoas não psicóticas, pois aqui esse fluxo temporal é rígido, limitado e direcionado a um único tema: o câncer de seu marido. Binswanger (1965/2010) lembra que seu interesse pelas formas de delírio de perseguição não era apresentar suas explicações, mas alcançar a constituição e a possibilidade de um novo fluxo temporal sem estar rígido nem fixado a uma única cena, como ele havia identificado no caso de Suzanne Urban através do congelamento de sua existência na possibilidade de morte de seu marido.

\section{Considerações finais}

Dentre as contribuições oferecidas pela clínica fenomenológica de Binswanger, uma das principais é apontar para a necessidade de compreender o sentido da existência da psicose para aquele paciente através de sua história de vida e como este se relaciona com as três formas de experienciar de mundo: 1) Umwelt - mundo natural; 2) Mitwelt - mundo social; e 3) Eigenwelt - mundo próprio. Em sua segunda fase, sob influência da filosofia existencial de Heidegger, Binswanger identifica as estruturas existenciais nos psicóticos que se apresentam com uma falha, quer dizer, como apontado no caso de Lola Voss, como um esvaziamento existencial, pois ela sente-se desconectada do Umwelt, gerando um constante pavor de que, a qualquer 
momento, possa despencar de sua existência e, para evitar isso, ncecessita de muletas para se sustentar no mundo e acabar com sua angústia.

Outra influência heideggeriana para Binswanger é encontrada na compreensão da ausência de brilho no Dasein tanto em Lola quanto em Suzanne Urban, ao destacar as formas de desproporções antropológicas dessas existências, assim como apontamos acima no caso clínico de Suzanne ao descrever a presunção como uma dessas formas inautênticas. A desproporção existencial permite apresentar a importância do estudo do homem em suas relações com os três mundos e com suas patologias, como o delírio, por exemplo.

Os casos clínicos apresentados neste artigo estimulam a compreensão do mundo de um Dasein com sua existência desproporcional, o que leva a clínica fenomenológica de Binswanger a se direcionar a uma compreensão existencial dos psicóticos. Em sua última fase fenomenológica, o retorno às obras de Husserl oferece a Binswanger mais ferramentas para aprofundar sua análise em um viés constitutivo desta experiência psicótica. A segunda análise do caso de Suzanne ilustra essa retomada dos textos husserlianos em seu caráter genético, pois Binswanger se direciona a uma compreensão da psicose levando em conta as falhas temporais do fluxo da experiência humana, como no caso de Suzanne, em que o foco é compreender sua existência através de seu fluxo temporal rígido, limitado e direcionado a um único tema, o câncer de seu marido.

\section{Referências}

Bin, K. (1998, dez.). Temporalidade da esquizofrenia. Revista Latinoamericana de Psicopatologia Fundamental, 1(4), 30-54. (Trabalho original publicado em 1976).

Binswanger, L. (1965). Psiquiatría existencial. Santiago, CH: Universitaria.

Binswanger, L. (1971). De la Phénoménologie. In Introduction à l'analyse existentielle (pp. 79-117). Paris, FR: Les Éditions de Minuit. (Trabalho original publicado em 1922).

Binswanger, L. (2004). Le cas Suzanne Urban: étude sur la schizophrénie. Saint Pierre de Salerne, FR: Gérard Monfort. (Trabalho original publicado em 1952).

Binswanger, L. (2010). Délire. Grenoble, FR: Jérôme Millon. (Trabalho original publicado em 1965).

Cabestan, P., \& Dastur, F. (2011). Daseinsanalyse. Paris, FR: Librairie philosophique J. Vrin.

Cabestan, P. (2011). Résistance. Binswanger et la psychanalyse freudienne. In 


\section{ARTIGOS}

B. Leroy-Viémon, Ludwig Binswanger: philosophie, anthropologie clinique, daseinsanalyse (pp. 165-183). Argenteuil, FR: Le Cercle Herméneutique Editeur.

Chamond, J. (2011, jan-jun). Fenomenologia e psicopatologia do espaço vivido segundo Ludwig Binswanger: uma introdução. Revista da Abordagem Gestáltica, XVII(1), 3-7.

Coelho Junior, N. E. (2001, fev.). A superação da dualidade interno/externo nas teorias fenomenológicas de Binswanger e Merleau-Ponty. Revista Latinoamericana de Psicopatologia Fundamental, IV(2), 11-17.

Fédida, P. (1970). Préface. In L. Binswanger, Analyse existentielle et psychanalyse freudienne: discours, parcours et Freud. Paris, FR: Gallimard.

Gros, C. (2009). Ludwig Binswanger: entre phénoménologie et expérience psychiatrique. Chatou, FR: Les Éditions de La Transparence.

Holanda, A. F. (2011). Gênese e histórico da psicopatologia fenomenológica. In V. Angerami-Camon (Org.), Psicoterapia e brasilidade (pp. 57-82). São Paulo, SP: Cortez.

Huygens, A. (2011). De la psychanalyse à l'analyse du Dasein: au-delà d'un passage, un saut. In B. Leroy-Viémon, Ludwig Binswanger: philosophie, anthropologie clinique, daseinsanalyse (pp. 269-287). Argenteuil, FR: Le Cercle Herméneutique Editeur.

Kuhn, R. (2002). L'œuvre de Ludwig Binswanger, son origine et sa signification pour l'avenir. In Fédida, P., \& Wolf-Fédida, M. Phénoménologie, Psychiatrie, Psychanalyse (pp. 35-45). Paris, FR: Colletion Phéno.

Pita, J., \& Moreira, V. (2013, oct-dez). As fases do pensamento fenomenológico de Ludwig Binswanger. Revista Psicologia em Estudo, 18(4), 679-687.

Tatossian, A. (2006). A fenomenologia das psicoses (J. C. Célio, trad.; V. Moreira, rev. tec.). São Paulo, SP: Escuta. (Trabalho original publicado em 1979).

Teixeira, J. A. C. (1997). Introdução às abordagens fenomenológica e existencial em psicopatologia: as abordagens existenciais. Análise Psicológica, 2(XV), 195-205.

\section{Resumos}

(Ludwig Binswanger's clinic inspired by Heidegger's Dasein and Husserl's genetic phenomenology)

Ludwig Binswanger's phenomenological clinic provides a new understanding of psychopathologies by highlighting the importance of patients'life stories. It is divided into three phenomenological stages and shows how fertile his psychopathological studies became after he had read Being and Time and due to Husserl's influence, 
which he undertook to investigate the formation of delusional experience. This article presents two clinical cases, Lola Voss and Suzanne Urban, to illustrate Ludwig Binswanger's contribution to phenomenological psychopathology in its second and final stage.

Key words: Binswanger, phenomenological psychopathology, clinical cases, delirium

(La clinique de Ludwig Binswanger inspirée par le Dasein de Heidegger et par la phénoménologie génétique de Husserl)

La clinique phénoménologique de Ludwig Binswanger propose une nouvelle compréhension de la psychopathologie soulignant l'importance de l'histoire de vie du patient. Les trois phases de sa pensée phénoménologique montrent la fécondité de ses études psychopathologiques, influencées par la lecture de l'Être et Temps et par Husserl, qu'il menait pour élucider la formation de l'expérience délirante. Cet article présente deux cas cliniques, Lola Voss et Suzanne Urban, qui illustrent la contribution apportée par Ludwig Binswanger à la psychopathologie phénoménologique dans sa deuxième et dernière phase.

Mots clés: Binswanger, psychopathologie phénoménologique, cas cliniques, delire

(La clínica de Ludwig Binswanger inspirada en el Dasein de Heidegger y en la fenomenología genética de Husserl)

La clínica fenomenológica de Ludwig Binswanger propone una nueva comprensión de la psicopatología al destacar su importancia en la historia de vida del paciente. Está divida en tres fases, mostrando la fertilidad de sus estudios psicopatológicos tras la lectura de Ser y tiempo, y a través de la influencia de Husserl, a fin de aclarar la constitución de la experiencia delirante. Este artículo tiene como objetivo presentar dos casos clínicos, Lola Voss y Suzanne Urban, para ilustrar la contribución de Ludwig Binswanger a la psicopatología fenomenológica en su segunda y última fase.

Palabras clave: Binswanger, psicopatología fenomenológica, casos clínicos, delirio

Citação/Citation: Pita, J., \& Moreira, V. (2020, dezembro). A clínica de Ludwig Binswanger inspirada no Dasein de Heidegger e na fenomenologia genética de Husserl. Revista Latinoamericana de Psicopatologia Fundamental, 23(4), 711-723. http://dx.doi.org/10.1590/ 1415-4714.2020v23n4p711.3.

Editor/Editor: Prof. Dr. Manoel T. Berlinck (in memoriam)

Submetido/Submitted: 16.1.2016/1.16.2016 Aceito/Acepted: 15.6.2016/6.15.2016 


\section{ARTIGOS}

Copyright: (C) 2009 Associação Universitária de Pesquisa em Psicopatologia Fundamental/ University Association for Research in Fundamental Psychopathology. Este é um artigo de livre acesso, que permite uso irrestrito, distribuição e reprodução em qualquer meio, desde que o autor e a fonte sejam citados / This is an open-access article, which permits unrestricted use, distribution, and reproduction in any medium, provided the original authors and sources are credited.

Financiamento/Funding: Este trabalho não recebeu apoio / This work received no funding.

Conflito de interesses/Conflict of interest: As autoras declaram que não há conflito de interesses. / The authors declare that there is no conflict of interest.

Juliana Pita

Psicoterapeuta; Doutora em psicologia clínica em cotutela (Unifor-ParisVI); Mestre (FUNCAP) em psicologia clínica pela Universidade de Fortaleza - Unifor (Fortaleza, CE, Br); Professora no curso de Psicologia na Unifor e membro do APHETO - Laboratório de Psicopatologia e Clinica Humanista Fenomenológica (Fortaleza, CE, Br).

Rua Antonio Lima, 188/400 - Meireles

Fortaleza, CE, Br.

julianapitap@gmail.com.

https://orcid.org/0000-0001-8859-4752

\section{Virgínia Moreira}

Psicoterapeuta; Doutora em psicologia clínica pela Pontifícia Universidade Católica de São Paulo - PUC-SP (São Paulo, SP, Br) e pós-doutora em antropologia médica pela Harvard University, como pesquisadora Fulbright. É professora titular da Universidade de Fortaleza - Unifor (Fortaleza, CE, Br); Supervisora clínica credenciada pela Sociedad Chilena de Psicológia Clínica; Membro da World Association of Person Centered and Experiential Psychoterapies; Membro da Associação Universitária de Pesquisa em Psicopatologia Fundamental (São Paulo, SP, Br); Orientadora de Doutorado em cotutela na Université Paris-Diderot - Paris VII. Tem Produtividade em Pesquisa nível 2 - CNPq. Rua Osvaldo Cruz, 241/901 - Meireles

Fortaleza, CE, Br. virginiamoreira@unifor.br.

http://orcid.org/0000-0003-2740-0023

This is an open-access article, which permits unrestricted use, distribution, and reproduction in any medium for non-commercial purposes provided the original authors and sources are credited. 